\title{
The mycotoxin deoxynivalenol activates GABAergic neurons in the reward system and inhibits feeding and maternal behaviours
}

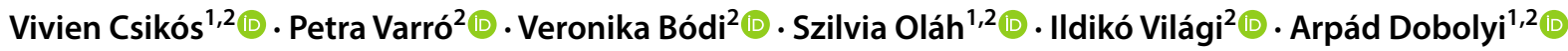

Received: 16 December 2019 / Accepted: 20 May 2020 / Published online: 29 May 2020

(c) The Author(s) 2020

\begin{abstract}
Deoxynivalenol (DON) or vomitoxin, is a trichothecene mycotoxin produced mainly by Fusarium graminearum and culmorum. Mycotoxins or secondary metabolic products of mold fungi are micro-pollutants, which may affect human and animal health. The neuronal and behavioural actions of DON were analysed in the present study. To address, which neurons can be affected by DON, the neuronal activation pattern following intraperitoneal injection of DON $(1 \mathrm{mg} / \mathrm{kg}) \mathrm{was}$ investigated in adult male rats and the results were confirmed in mice, too. DON-induced neuronal activation was assessed by c-Fos immunohistochemistry. DON injection resulted in profound c-Fos activation in only the elements of the reward system, such as the accumbens nucleus, the medial prefrontal cortex, and the ventral tegmental area. Further double labelling studies suggested that GABAergic neurons were activated by DON treatment. To study the behavioural relevance of this activation, we examined the effect of DON on feed intake as an example of reward-driven behaviours. Following DON injection, feed consumption was markedly reduced but returned to normal the following day suggesting an inhibitory action of DON on feed intake without forming taste-aversion. To further test how general the effect of DON on goal-directed behaviours is, its actions on maternal behaviour was also examined. Pup retrieval latencies were markedly increased by DON administration, and DON-treated mother rats spent less time with nursing suggesting reduced maternal motivation. In a supplementary control experiment, DON did not induce conditioned place preference arguing against its addictive or aversive actions. The results imply that acute uptake of the mycotoxin DON can influence the reward circuit of the brain and exert inhibitory actions on goal-directed, reward-driven behaviours. In addition, the results also suggest that DON exposure of mothers may have specific implications.
\end{abstract}

Keywords Mycotoxin $\cdot$ Deoxynivalenol $\cdot \mathrm{c}$-Fos $\cdot$ Feeding $\cdot$ Maternal behaviour $\cdot$ Female rat

\section{Introduction}

Mycotoxins represent a significant health challenge to animals and humans, too, as they may be digested with infected cereals, such as wheat, barley, rye, rice, and maize (Pestka 2010). Deoxynivalenol (DON) is one of the most abundant and economically most important mycotoxins. This trichothecene structured toxin is mainly produced

Arpád Dobolyi

dobolyi.arpad@ttk.elte.hu

1 MTA-ELTE Laboratory of Molecular and Systems Neurobiology, Department of Physiology and Neurobiology, Eötvös Loránd University and the Hungarian Academy of Sciences, Budapest, Hungary

2 Department of Physiology and Neurobiology, Institute of Biology, Eötvös Loránd University, Budapest, Hungary by Fusarium graminearum and culmorum. The appearance of these Fusarium species is on the rise due to global warming. Numerous studies have documented that DON is heat stable. Therefore, it withstands cooking and cereal processing, which increases the risk of its occurrence in food (Hughes et al. 1999; Schothorst and van Egmond 2004; Turner et al. 2010). For this reason, DON has been implicated in mycotoxicosis. Furthermore, it was also established that DON can penetrate the blood-brain barrier (Behrens et al. 2015) and thus, directly modulate brain activity even if DON entered the brain more slowly and peaked at lower concentrations compared to other tissues, such as heart, spleen, kidney or liver (Pestka et al. 2008). A variety of different effects of DON have previously been proposed. It was shown to bind to the $60 \mathrm{~S}$ ribosomal subunit and inhibit the biosynthesis of protein, a potential background mechanism of its cytotoxic effects. DON has 
negative effects on the immune system and causes intestinal inflammation (Awad et al. 2013; Pestka 2010). Other studies reported that low concentrations of DON (less than $5 \mathrm{mg} / \mathrm{kg}$ feed) stimulated the immune system while high concentrations suppressed the immune responses (Pestka 2003). Moreover, DON induced anorexia (Lebrun et al. 2015) through the brain serotonin pathways or by a direct effect on the gut microbiota (Peng et al. 2017). DON may also affect other monoamine systems, e.g. 6 weeks long DON treatment increased the dopamine and noradrenaline levels in different brain regions in mice (Al-Hazmi et al. 2015). In addition, cardiac dysfunction and transient negative effects on the autonomous nervous system were also observed in rats (Ngampongsa et al. 2011).

A possible way to explore the site of actions of DON in the brain is to examine if DON increases neuronal activation, and if yes, in which brain areas. Visualization of the immediate early gene c-Fos is a generally used and suitable marker to assess increased neuronal activity at a high resolution as the presence of c-Fos can be detected in individual cells (Herrera and Robertson 1996). c-Fos is expressed in neurons if their activity is elevated. Even if one must bear in mind that not all activated neurons show c-Fos induction, and that the threshold of c-Fos protein induction may differ between subpopulations of neurons, mapping of c-Fos expression is a useful approach to identify and investigate neuronal groups activated in response to different challenges throughout the brain (Perez-Cadahia et al. 2011). Importantly, the c-Fos technique can be used to establish the brain site of action of toxins, including DON. Indeed, some research groups have used this method to identify brain structures activated in response to DON intoxication. c-Fos activation was found in the accumbens nucleus (NAc), paraventricular nucleus of the hypothalamus, paraventricular nucleus of the thalamus, and the locus coeruleus following a low dose (100 $\mu \mathrm{g} /$ $\mathrm{kg} /$ day) chronic DON treatment (Faeste et al. 2019). Acute oral exposure to DON at a high dose $(5 \mathrm{mg} / \mathrm{kg})$ induced c-Fos labelling in circumventricular organs and surrounding structures (Girardet et al. 2011a). Furthermore, neurons were activated in the nucleus of the solitary tract in mice after $12.5 \mathrm{mg} / \mathrm{kg}$ acute oral DON treatment and $15 \%$ of the activated neurons were tyrosine-hydroxylase (TH)-positive (Girardet et al. 2011b). The same research group also reported c-Fos activation in the central nucleus of the amygdala and the dorsolateral division of the bed nucleus of the stria terminalis after $12.5 \mathrm{mg} / \mathrm{kg}$ DON treatment using gavage intubation needle. They also showed that DON administration decreased both meal frequency and size (Girardet et al. 2011b) suggesting nausea-induced anorexia. These experiments suggest that DON can act on the central nervous system, but the doses used in these studies were above the EU tolerable daily intake limit of DON. Therefore, we have chosen lower doses for our studies.
Reward plays a major role in different types of goaldirected behaviours, for example, feed intake, sexual activity, and maternal care (Schultz 2015). The major component of the brain reward network is the NAc, the medial prefrontal cortex (MPFC), and the ventral tegmental area (VTA) (Kelley and Berridge 2002). Dopaminergic neurons in the VTA project to the NAc and the MPFC in the mesolimbic pathway (Kardos et al. 2019; Schultz 2015). Rewarding stimuli increase the activity of dopaminergic neurons in the VTA, whereas aversive stimuli mostly inhibit their activity (Cohen et al. 2012; Matsumoto and Hikosaka 2009). The NAc has been divided into a core and a shell region, which may be implicated in different aspects of reward processing ( $\mathrm{Li}$ et al. 2018). The GABAergic medium spiny neurons are the major projection cells in the NAc while local inhibitory GABAergic neurons are also present including those expressing parvalbumin (Yager et al. 2015). In the present study, we addressed the effect of DON of neuronal activation in the brain including the reward system. We attempted to identify the neurochemical characteristics of the activated neurons using double immunolabeling in rats and c-Fos labelling of DON treated transgenic mice whose GABA-ergic cell bodies contained green fluorescence. We also investigated the effect of DON on the feeding and maternal behaviour in the rat. For feeding, we chose a paradigm, in which the effect of a bolus injection of a drug, here DON, can be investigated (Fuller and Snoddy 1968). We chose maternal care as the other motivated behaviour to be examined, in which the NAc plays a crucial role (Olazabal et al. 2013; Salgado and Kaplitt 2015; Smith and Holland 1975).

\section{Materials and methods}

\section{Animals and housing conditions}

All procedures involving rats were carried out according to experimental protocols approved by the Animal Examination Ethical Council of the Animal Protection Advisory Board at Eötvös Loránd University, Budapest, and met the guidelines of the Animal Hygiene and Food Control Department, Ministry of Agriculture, Hungary. All efforts were made to minimize the number of animals used and their suffering. The animals were kept in standard laboratory conditions; the temperature was kept constant $\left(23 \pm 1{ }^{\circ} \mathrm{C}\right)$ in $50-60 \%$ humidity, with 12 -h light-dark cycle (lights on at 6:00 AM). All experimental procedures were conducted in a separate procedure room where the animals were kept for the entire experiment. The animals were supplied with feed (SM R/M-H, 1534-00; Ssniff, Soest, Germany) and drinking water ad libitum except for rats under the fasting protocol. Two rats were housed together in a cage for the rat experiments. For the mice studies, four mice were 
housed together per cage. To avoid stress for mice, rats and mice cages were kept in separate rooms. A total of 43 male (310-340 g) and 48 female (200-300 g) Wistar rats (ToxiCoop, Budapest, Hungary) and 8 VGAT-IRES-Cre/ GT(ROSA)26Sor_CAG/ZsGreen1 mice (VGAT-IRES-Cre mice crossed with $\mathrm{Gt}(\mathrm{ROSA})$ CAG/ZsGreen 1 mice) were used in the study. Both transgenic mouse lines were obtained from The Jackson Laboratory (Bar Harbor, Maine, United States). Female mice were 3-6 months old when mated with males with the other genotype so that all pups contained both genotypes. Therefore, genotyping after breeding was not performed in the crossed mice. It was also not needed because of the appearance of fluorescence in GABA-ergic neurons in histological sections of their brains. ZsGreen, a modified green fluorescent protein, is frequently used in histological studies of transgenic mouse models as it has bright fluorescence with high photo-stability, which is not affected by paraformaldehyde fixation and ensures excellent detail within fixed tissue (Wouters et al. 2005). In the applied mouse line, ZsGreen was expressed by the promoter of the vesicular GABA transporter (VGAT) to visualize GABAergic neurons using VGAT as a specific marker of this type of cells (McIntire et al. 1997).

\section{DON treatment}

Deoxynivalenol (DON) was purchased from Tocris Bioscience (Bristol, United Kingdom, product number: 3976). It was dissolved in physiological saline solution before administration to the animals. DON was injected intraperitoneally (i.p.) to rats and mice in a dose of $1 \mathrm{mg} / \mathrm{kg} \mathrm{bw}$, while control animals received physiological saline injections.

\section{Tissue collection for immunolabeling}

Two hours after DON (or control saline) injection, the animals were sacrificed with an intraperitoneal injection of urethane (4\% dissolved in saline), $1 \mathrm{ml}$ for rats, and $0.1 \mathrm{ml}$ for mice. Then, the animals were transcardially perfused first with saline to remove the blood and then with $4 \%$ paraformaldehyde prepared in $0.1 \mathrm{M}$ phosphate buffer (PB; $\mathrm{pH}=7.4$; Sigma, St. Louis, Missouri, United States, catalogue numbers: 71500 and S0876). Brains were removed, postfixed in $4 \%$ paraformaldehyde for a day, and then transferred to PB containing $20 \%$ sucrose for an additional day for cryoprotection. Serial free-floating coronal sections were cut at $50 \mu \mathrm{m}$ thickness for rats and $40 \mu \mathrm{m}$ thickness for mice with cryostat (Leica CM1520). Sections were collected in PB containing $0.1 \%$ sodium azide in parallels ( 5 parallels for rats and 3 for mice). The parallels were used separately for individual staining of c-Fos and c-Fos double labelling. The sections were stored at $4{ }^{\circ} \mathrm{C}$ until immunohistochemical procedures started.

\section{c-Fos immunolabeling in rats and mice}

Every fifth $50-\mu \mathrm{m}$-thick free-floating coronal brain section of DON injected, and control injected rats ( $n=6$ per group) and every third $40-\mu \mathrm{m}$-thick free-floating coronal brain section of DON injected, and control injected mice $(n=4$ per group) was processed for c-Fos immunohistochemistry as described previously (Olah et al. 2018). Sections were pretreated in PB containing 0.3\% hydrogen peroxide (Sigma, St. Louis, Missouri, United States, catalogue number: H1009) for $15 \mathrm{~min}$ for quenching of endogenous peroxidase activity. Then, the sections were incubated in PB containing $0.5 \%$ Triton X-100 (Sigma, St. Louis, Missouri, United States, catalogue number: $\mathrm{X} 100$ ) and 3\% bovine serum albumin (BSA; Sigma, St. Louis, Missouri, United States, catalogue number: A3294) for 1-h. Sections were then incubated in anti-c-Fos antiserum (1:6000, Abcam, Cambridge, United Kingdom, catalogue number: ab190289) at room temperature for two nights. Following the primary antibody, the sections were incubated in biotin-conjugated anti-rabbit secondary antibody (1:800; Jackson ImmunoResearch West Grove, Pennsylvania, United States, catalogue number: 711065-152) for $1 \mathrm{~h}$ and then in avidin-biotin-peroxidase complex (ABC; 1:500; Vector Laboratories, Burlingame, United States, catalogue number: PK6100) for $1 \mathrm{~h}$. The labelling was visualized by nickel-2'-diaminobenzidine (DAB) peroxidase technique (Sigma, St. Louis, Missouri, United States, catalogue numbers: D5637 and N4882). Briefly, the sections were then treated with $0.06 \% \mathrm{DAB}$ and $0.003 \% \mathrm{H} 2 \mathrm{O} 2$ in Tris hydrochloride buffer $(0.05 \mathrm{M}, \mathrm{pH}=8.2)$ containing $0.2 \%$ nickel-sulphate for $10 \mathrm{~min}$. Sections were then mounted, dried, and coverslipped with Depex mounting medium (Sigma, St. Louis, Missouri, United States, catalogue number: 06522).

\section{Double immunolabeling in rats}

Every fifth $50-\mu \mathrm{m}$-thick free-floating brain section from the relevant regions (NAc, VTA, MPFC) of DON injected and control injected rats was processed first for c-Fos immunohistochemistry as described earlier, except that the signal was visualized by incubation in fluorescein isothiocyanatetyramide (FITC tyramide; 1:8000) and $0.001 \%$ hydrogen peroxide in Tris-hydrochloride buffer $(0.1 \mathrm{M}, \mathrm{pH}=8.0)$ for 6 min instead of DAB. Subsequently, the sections were incubated in mouse anti-tyrosine hydroxylase $(\mathrm{TH})$ antiserum (1:5000; Chemicon, Temecula, California, United States, catalogue number: MAB5280) or mouse anti-parvalbumin antiserum (1:1000; Sigma, St. Louis, Missouri, United States, catalogue number: P3088) for overnight at room temperature, and then in Alexa 594 donkey anti-mouse (1:500, Jackson ImmunoResearch, catalogue number: 715585-150) for $1 \mathrm{~h}$. Sections were then mounted, dried, and 
coverslipped with Aqua-Poly/Mount (Polyscience, catalogue number: 18606).

\section{Double labelling of c-Fos and GABA-ergic neurons in mice}

VGAT-IRES -Cre/GT(ROSA)26Sor_CAG/ZsGreen1 mice were injected with DON and control saline injection. Every third $40 \mu \mathrm{m}$-thick free-floating brain section from the relevant regions (NAc, VTA, MPFC) of DON injected and control injected mice was processed for c-Fos fluorescence immunohistochemistry as described earlier, except that the signal was visualized by incubation in Alexa 488 donkey anti-rabbit secondary antibody (1:500, Jackson ImmunoResearch, West Grove, Pennsylvania, United States, catalogue number: 711-545-152) for $1 \mathrm{~h}$. Sections were then mounted, dried, and coverslipped with Aqua-Poly/Mount (Polyscience, Hirschberg an der Bergstrasse, Germany, catalogue number: 18606).

\section{Analysis and quantification of c-Fos and double labelled cell numbers in rats and mice}

Brain areas were identified using the Paxinos and Watson stereotaxic atlas of the rat brain (Franklin and Paxinos 1997; Paxinos and Watson 2005). The brain areas containing Fos-immunoreactive (Fos-ir) cells were detected and captured with a light microscope equipped with epifluorescent illumination (Nikon Eclipse Ni) and a digital 2MP Slider CCD camera (Diagnostic Instruments, Sterling Heights, MI, USA) using 4-40× objectives and Spot RT3 software. The images of fluorescence double immunolabeling were taken with a confocal microscope (Zeiss LSM 800 Confocal Microscope) using 40-60× objectives. There were at least 5 z-stack images taken for each field for the analysis of double labelling at an optical thickness of 2-5 $\mu \mathrm{m}$. Contrast and sharpness of the images were adjusted using the "levels" and "sharpness" commands in Adobe Photoshop CS 8.0. Full resolution was maintained until the photomicrographs were cropped and assembled.

The numbers of c-Fos-, and the double-labelled neuronal cell bodies were counted in brain areas where we observed a considerably high number of increased c-Fos-positive cells following DON injection. The images were coded and the person counting the cells was not aware of which experimental group the images belonged to. The numbers of c-Fos-, TH-, parvalbumin-positive or GABAergic neuronal cell bodies were counted in the coronal section where the size of the anatomical structure was the largest so that the highest number of immunolabeled cells can be observed in the brain area. In addition, cells were also counted in the previous and following Sects. (200 $\mathrm{mm}$ apart in the rats and $120 \mathrm{~m}$ apart in the mice). Thereby, the same anatomical locations were analysed in each animal.

Data from all 6 rats per group ("DON injected" and "saline-injected control" groups) and all 4 mice per group were analysed, and the density of labelled neurons was expressed as the cell number $/ \mathrm{mm}^{2}$. The total number of Fosir neurons in activated regions was counted using ImageJ software, version 1.50i (ImageJ, RRID:SCR_003070, Wayne Rasband, National Institute of Health, Bethesda, MD) in photomicrographs. Statistical analysis was performed using Student's $t$ test for each brain region. All statistics were performed with Prism 6 for Windows (GraphPad Software, La Jolla, CA).

\section{Measurement of feeding}

The test lasted for 6 days (days 0-5), during which male and female rats ( $n=20$ males and 20 females) were kept alone in a cage. The animals were separated in the morning and were feed deprived in the evening on day zero. The experiment consisted of a training and a testing phase. The training phase was on days $1-3$. On these days, the animals received feed between 10.00 to $12.00 \mathrm{AM}$. Within the $2 \mathrm{~h}$, all animals had full access to feed. The testing phase consisted of days 4 and 5. The animals received i.p. DON $(1 \mathrm{mg} / \mathrm{kg})$ or saline injection at $9 \mathrm{AM}, 1 \mathrm{~h}$ before feeding on the 4 th day. On the 5th day, animals received a saline injection at $9 \mathrm{AM}, 1 \mathrm{~h}$ before the access to feed. The amounts of consumed feed and water were measured every day before and after feeding. The weight of the animals was also measured before and after the feeding on each day to establish the effect of DON on feed intake. The protocol is summarized in Fig. 1. For a better comparison of the data, relative feed intake was calculated as the percentage of daily feed intake/body weight. The statistical analysis was carried out on this parameter with GraphPad Software using Repeated Measure 2-way ANOVA test with the type of treatment (DON vs. saline) being one parameter and the day being the repeated parameter so that to compare the maternal performance of the rat with her previous day performance.

\section{Measurement of maternal behaviour}

Spontaneous maternal behaviour was measured as reported previously (Leko et al. 2017). For mating, 2 females and a male rat were kept together for 2 weeks. Then, pregnant females and mothers $(n=10)$ were housed individually until the end of the experiment in a separate room dedicated to the experiment. The number of pups of the mother rats was reduced to 10 immediately after parturition. The maternal behaviour of the animals was examined on postpartum days 7-8. On the first test day, animals received saline injection as control. On the second test day, the treated group of the 


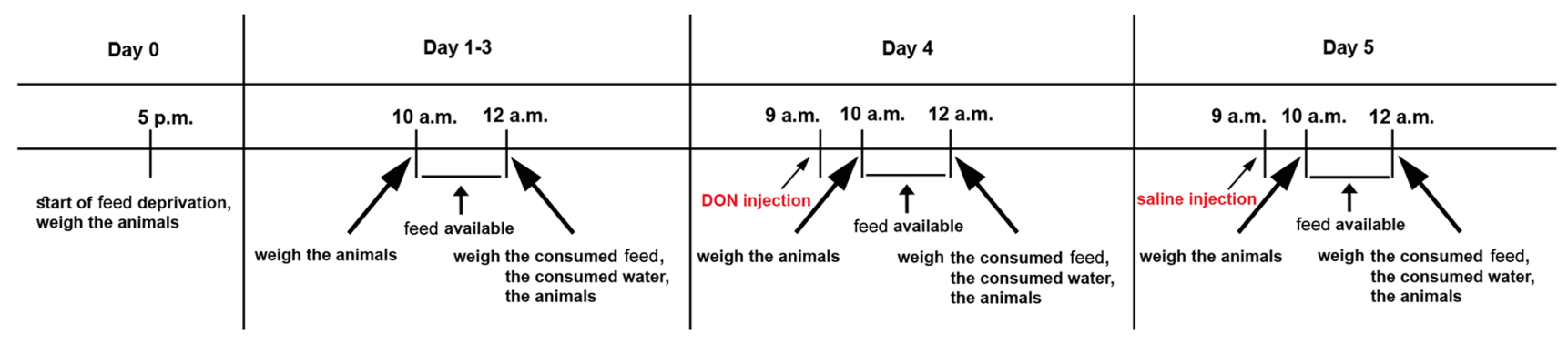

Fig. 1 Overview of the feed intake test. The animals are deprived from the feed one day before starting the test. On days 1-3, during the habituation period, the animals can take feed only for $2 \mathrm{~h}$ long daily. The weight of the animals and of the consumed feed, and water are measured. On day 4 , the animals are injected with DON (or saline

animals received DON (i.p. $1 \mathrm{mg} / \mathrm{kg}$ ) while the control group was injected with saline. The pups were removed from the mothers immediately before the injections. Pup retrieval tests were performed at 30 and $60 \mathrm{~min}$ after the injections. The pups were placed in corners opposite to the nest in the cage. The mothers took the pups back to the nest one by one, the timing of which was registered. The pup retrieval test took a maximum of $5 \mathrm{~min}$. After the second pup retrieval test, the spontaneous maternal behaviour of the mothers was also videotaped. The videotapes were evaluated with Solomon Coder software (Version: Beta: 2016.06.26.) by an individual blind to the genotype. The time spent in the nest, the duration of suckling, kyphosis, nest building, grooming of pups, self-grooming, and exploration outside of the nest were measured.

The effect of DON on pup retrieval was assessed by the retrieval time of the 1st, 3rd, and last pup (10th). Spontaneous maternal behaviour was analysed based on the pup-associated (suckling, kyphosis, nest building, and grooming of pups) and the non-pup associated (exploration, self-grooming) behaviours. The statistical analysis was carried out with GraphPad Software using 2-way Repeated Measure ANOVA test with the day (that is treatment, as rats received saline the first day and DON on the second day) being one parameter, and the number of pups (first, third, or last) being the other parameter. Both parameters were set as repeated measures to compare the maternal performance of the rat with her previous day performance.

\section{Conditioned place preference test}

To measure the addictive or aversive effect of DON, conditioned place preference was investigated as described before (Cunningham et al. 2006; Cservenak et al. 2013). Male and female rats ( $n=11$ males and 8 females) were kept alone in a cage starting 3 days before the experiment. The experiment itself took 4 days and consisted of a 3-day place conditioning while testing was performed on the 4th day (Fig. 2). in the control group) $1 \mathrm{~h}$ before the feeding period. The schedule of measurements is the same as for the habituation days. On day 5, the protocol for day 4 was performed using saline injection instead of DON to examine the return of feed intake to the control value following DON administration the previous day

For training, each animal received i.p. DON (in a dose of $1 \mathrm{mg} / \mathrm{kg}$ ) or physiological saline injection in the morning and the other type of injection in the afternoon. $30 \mathrm{~min}$ after the injection, the animals were transferred to a special environment (new cage). There were 2 types of new cages, which both differed from the usual cage of the rats in colour and the object placed in them. The test cages were all blue, but half of them were marked with white adhesive patches. Moreover, a triangular purple or a round orange bowl was placed into the cage so that the animals could distinguish the two test cages (Fig. 2). Each animal was placed into the same type of cage following the same treatment so that the environment could be associated with the type of injection (DON vs. saline). Half of the rats received DON in one type of cage, the other half of the rats was injected with DON in the other type of cage in order to eliminate the possibility that the rats prefer one type of the cage rather than stay there altered time because of DON treatment. On the test day, the animals were placed into the test apparatus without any injection. The apparatus consisted of the 2 types of cages representing the special environment previously associated with DON or saline (Fig. 2). The 2 cages were connected with a tube so that the animals could freely choose which cage they opt to stay in. The apparatus was cleaned with $70 \%$ ethanol solution after each test to remove odour trails. The test lasted for $45 \mathrm{~min}$, during which the apparatus was videotaped. The videotapes were later analysed with Solomon Coder to measure the duration of time spent in each cage.

\section{Results}

\section{DON induced c-Fos activation}

In response to DON treatment, c-Fos-immunolabeled cells appeared in a few brain regions while the number of labelled cells was low in these regions following control injections (Table 1). The immunolabeling was present in 
Day $1,2,3$

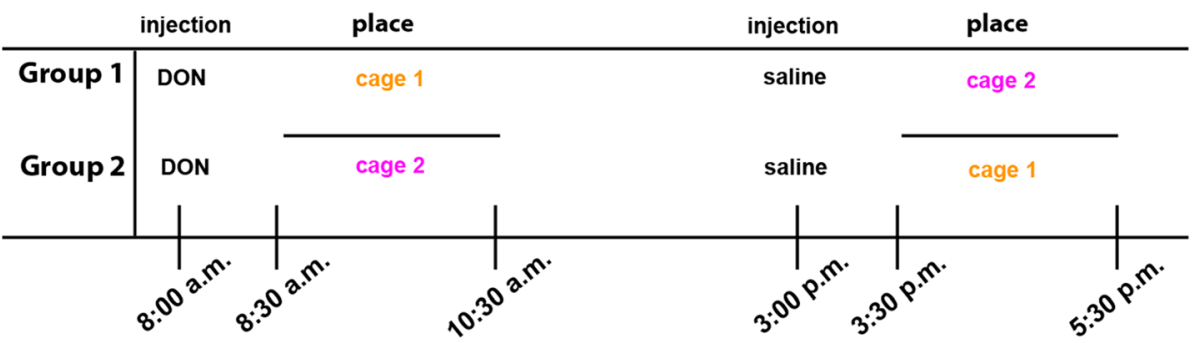

Day 4

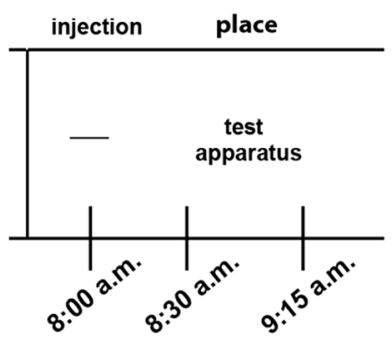

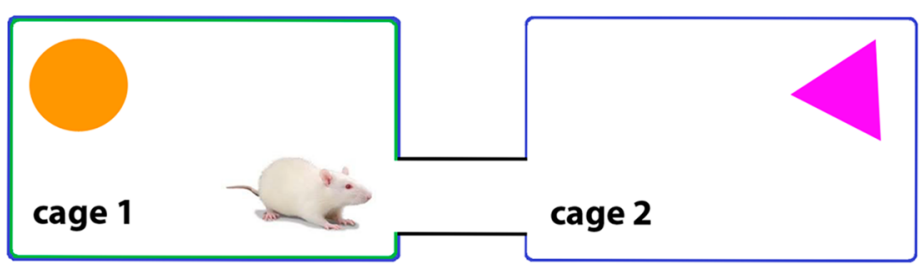

Fig. 2 Overview of the conditioned place preference test. The upper left panel shows the protocol of establishing DON association. The 2 different cages are represented by orange and purple objects in them while the pattern on the wall of the cages was also different as shown schematically in the lower panel. The two groups differed in which type of cage was used for association with DON, that is in which cage DON was administered. The animals spent an equal amount of time

roundish dot-like structures suggesting nuclear localization in some brain regions but was absent in other brain regions (Fig. 3). We quantitatively evaluated the density of c-Fos positive cells in brain regions where visual mapping suggested elevated density in response to DON as compared to control saline injections and in some brain regions, which were potentially implicated in DON actions based on previous literature. Marked differences were detected in the NAc, the VTA and the MPFC (infralimbic and prelimbic cortices) of rats (Figs. 4, 5). While the density of c-Fos positive cells in NAc of the DON injected rats was $233.6 \pm 39.7$ on a $1 \mathrm{~mm}^{2}$ - sized area, it was only $15.4 \pm 4.4$ cells $/ \mathrm{mm}^{2}$ in control rats. For a more detailed description of the activation of the NAc, c-Fos cell density was analysed separately in the shell and core areas of NAc. At bregma level +2.04, the density of c-Fos-positive cells was $260.1 \pm 30.9$ cells $/ \mathrm{mm}^{2}$ in the DON injected rats and $61.7 \pm 26.4$ cells $/ \mathrm{mm}^{2}$ in the control animals in the shell region. The density of c-Fos positive cells was $191.8 \pm 24.2$ cells $/ \mathrm{mm}^{2}$ in the DON injected animals in the core region of the NAc while $46.3 \pm 28.7$ positive cells $/ \mathrm{mm}^{2}$ were counted in the control rats in this region. The difference between the two groups was significant in both regions of the NAc $(p<0.01)$ based Student's t test (Fig. 4). In the mice, we found $277.7 \pm 50.7 \mathrm{c}$-Fos-positive cells $/ \mathrm{mm}^{2}$ in the whole NAc after DON injection, which increased significantly from $79.3 \pm 6.6$ cells $/ \mathrm{mm}^{2}$ in control mice.

In addition to the NAc, we also observed DON-induced neuronal activation in the VTA. The number of activated in the other type of cage, too, so that familiarity with the cage would be eliminated. On the test day (day 4), the rats were placed in the test apparatus, which consisted of the 2 cages but was connected so that the animals could freely opt where to stay. Their movement was monitored without injection to test if positive or negative associations were formed for DON

neurons in the VTA was $251.3 \pm 52.9 / \mathrm{mm}^{2}$ in DON injected (Fig. 5a) and $4.4 \pm 2.2$ cells $/ \mathrm{mm}^{2}$ in control rats (Fig. 5b). The result was significant $p<0.01$ ) based Student's t test in the mouse VTA, $238.0 \pm 81.6 \mathrm{c}$-Fos-positive cells $/ \mathrm{mm}^{2}$ were counted in treated and $136.7 \pm 37.5$ cells $/ \mathrm{mm}^{2}$ in control mice.

The MPFC was the third markedly activated brain region. The density of c-Fos-positive cells was $174.0 \pm 28.7$ cells/ $\mathrm{mm}^{2}$ in DON injected rats (Fig. 5d) while 50.7 \pm 15.4 cells/ $\mathrm{mm}^{2}$ were c-Fos-positive in the MPFC of the control animals (Fig. 5e). In the mouse MPFC, we found 138.9 \pm 6.3 activated cells $/ \mathrm{mm}^{2}$ after DON treatment, and $32.4 \pm 13.2$ cells $/ \mathrm{mm}^{2}$ at the control animals. The p-value was 0.006 with Student's t-test.

Other brain regions were microscopically analysed, too, but no marked change was observed between the DONtreated and control animals. These data are shown in Table 1. The density of the c-Fos positive cells is the average from the analysed 6 rats.

\section{Phenotypic characterization of DON-activated neurons}

In the NAc, the number of the c-Fos-positive cells was $385.7 \pm 35.3 / \mathrm{mm}^{2}$ in the mice while $484.9 \pm 44.1 \mathrm{GABAe}-$ rgic cells $/ \mathrm{mm}^{2}$ were counted. The number of double labelled cells was $299.8 \pm 28.7$ cells $/ \mathrm{mm}^{2}$. Thus, $78 \%$ of the GABAergic cells were c-Fos-positive, and $63 \%$ of the 
Table 1 The number of c-Fos positive cells in a variety of different brain regions including those potentially involved in the effect of DON

\begin{tabular}{|c|c|c|}
\hline \multirow[t]{2}{*}{ Brain area } & \multicolumn{2}{|c|}{$\begin{array}{l}\text { Number of c-Fos positive } \\
\text { cells }\end{array}$} \\
\hline & $\begin{array}{l}\text { Saline } \\
\text { injected } \\
\text { animals }\end{array}$ & $\begin{array}{l}\text { DON } \\
\text { injected } \\
\text { animals }\end{array}$ \\
\hline \multicolumn{3}{|l|}{ Cerebral cortex } \\
\hline \multicolumn{3}{|l|}{ Medial prefrontal cortex } \\
\hline Infalimbic cortex & + & ++++ \\
\hline Prelimbic cortex & + & ++++ \\
\hline Cingulate area & - & ++ \\
\hline Dorsal peduncular cortex & - & ++ \\
\hline Other parts of cerebral cortex & - & - \\
\hline \multicolumn{3}{|l|}{ Hippocampus } \\
\hline CA1 region & - & + \\
\hline $\mathrm{CA} 2$ region & + & - \\
\hline $\mathrm{CA} 3$ region & - & - \\
\hline Dentate gyrus & - & - \\
\hline \multicolumn{3}{|l|}{ Amygdala, septum } \\
\hline Central nucleus & + & ++ \\
\hline Basal nuclei & + & ++ \\
\hline Lateral nucleus & ++ & + \\
\hline Medial nucleus & + & ++ \\
\hline Medial septal nucleus & - & ++ \\
\hline Lateral septum ventral nucleus & - & ++ \\
\hline Lateral septum intermed. nucleus & + & + \\
\hline \multicolumn{3}{|l|}{ Indusium griseum } \\
\hline Subfornical organ & - & - \\
\hline Vascular organ of lamina terminalis & - & - \\
\hline Nucleus of the diagonal band & - & - \\
\hline \multicolumn{3}{|l|}{ Basal nuclei } \\
\hline Caudate-Putamen & + & + \\
\hline Accumbens nucleus & + & ++++ \\
\hline Globus pallidus & + & - \\
\hline Endopiriform nucleus & - & + \\
\hline Claustrum & ++ & + \\
\hline Ventral pallidum & - & + \\
\hline Substantia innominata & + & ++ \\
\hline \multicolumn{3}{|l|}{ Diencephalon } \\
\hline \multicolumn{3}{|l|}{ Thalamus } \\
\hline Anteromedial nucleus & + & + \\
\hline Anterodorsal nucleus & + & + \\
\hline Anteroventral nucleus & + & + \\
\hline Paraventricular nucleus & ++ & ++++ \\
\hline Midline and intralaminar nuclei & + & + \\
\hline Lateral nuclei & ++ & ++ \\
\hline Ventral nuclei & ++ & + \\
\hline Reticular nucleus & + & + \\
\hline \multicolumn{3}{|l|}{ Hypothalamus } \\
\hline Medial preoptic area & + & + \\
\hline
\end{tabular}

Table 1 (continued)

\begin{tabular}{|c|c|c|}
\hline \multirow[t]{2}{*}{ Brain area } & \multicolumn{2}{|c|}{$\begin{array}{l}\text { Number of c-Fos positive } \\
\text { cells }\end{array}$} \\
\hline & $\begin{array}{l}\text { Saline } \\
\text { injected } \\
\text { animals }\end{array}$ & $\begin{array}{l}\text { DON } \\
\text { injected } \\
\text { animals }\end{array}$ \\
\hline Lateral preoptic area & + & + \\
\hline Septohypothalamic nucleus & - & ++ \\
\hline Supraoptic nucleus & + & + \\
\hline Suprachiasmatic nucleus & - & - \\
\hline Anterior hypothalamic area & - & + \\
\hline Paraventricular nucleus & - & - \\
\hline Arcuate nucleus & ++ & ++ \\
\hline Lateral hypothalamic area & + & ++ \\
\hline Ventromedial nucleus & ++ & ++ \\
\hline Dorsomedial nucleus & + & ++ \\
\hline Posterior hypothalamic area & + & ++ \\
\hline Mamillary body & + & ++ \\
\hline \multicolumn{3}{|l|}{ Midbrain } \\
\hline Ventral tegmental area & + & ++++ \\
\hline Periaqueductal gray & - & ++ \\
\hline Substantia nigra & - & ++ \\
\hline Colliculus superior & - & ++ \\
\hline Colliculus inferior & - & - \\
\hline \multicolumn{3}{|l|}{ Hindbrain } \\
\hline \multicolumn{3}{|l|}{ Pons } \\
\hline Pontine nuclei & - & + \\
\hline Parabrachial nucleus & - & + \\
\hline Superior olive & - & - \\
\hline Inferior olive & - & - \\
\hline Nucleus of the trapezoid body & - & + \\
\hline Pontine reticular formation & - & - \\
\hline Sensory trigeminal nu. & - & - \\
\hline Pontine raphe nuclei & - & - \\
\hline Locus coeruleus & - & + \\
\hline Superior vestibular nucleus & - & + \\
\hline Medial vestibular nucleus & - & - \\
\hline Facial motor nucleus & - & - \\
\hline \multicolumn{3}{|l|}{ Medulla oblongata and cerebellum } \\
\hline Cochlear nuclei & - & + \\
\hline Gigantocellular reticular nucleus & - & - \\
\hline Spinal trigeminal nucleus & - & - \\
\hline Medullary reticular formation & - & - \\
\hline Inferior olive & - & - \\
\hline Nucleus of the solitary tract & - & + \\
\hline Area postrema & - & - \\
\hline Cerebellar cortex & - & - \\
\hline Deep cerebellar nuclei & - & - \\
\hline
\end{tabular}

$+:$ the number of cells per region on $1 \mathrm{~mm}^{2}$ in a typical section is $\geq 50 ;++: \geq 100 ;+++: \geq 150 ;++++: \geq 200$ 
Fig. 3 Some examples on the activation pattern of c-Fos in response to DON treatment. a c-Fos positive cells are shown in the paraventricular thalamic nucleus (PV) following DON administration. The abundant black dots represent the c-Fos positive cells. $\mathbf{b}$ The PV of a control (saline injected) animal contains less c-Fos positive cells than the DON injected animal, however, the density of labelled cells is still considerably high. In contrast to the PV, the area postrema (AP) and the nucleus of the solitary tract (NTS) do not express c-Fos either following DON (c), or following saline injection (d). The scale bar is $500 \mu \mathrm{m}$. $c c$ central canal, $C M$ central median nucleus, $M D$ mediodorsal thalamic nucleus, $3 V$ third ventricle, $4 V$ fourth ventricle
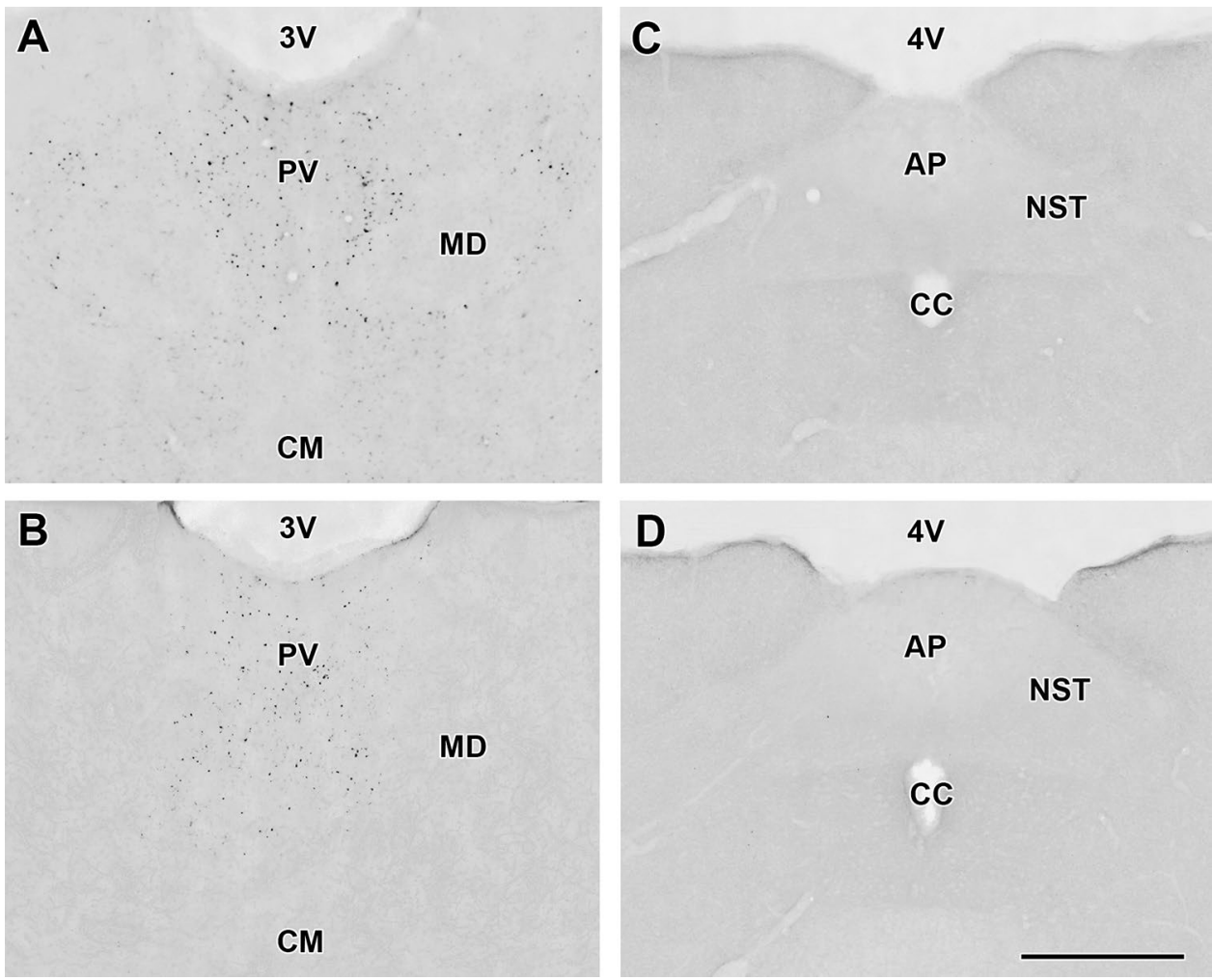
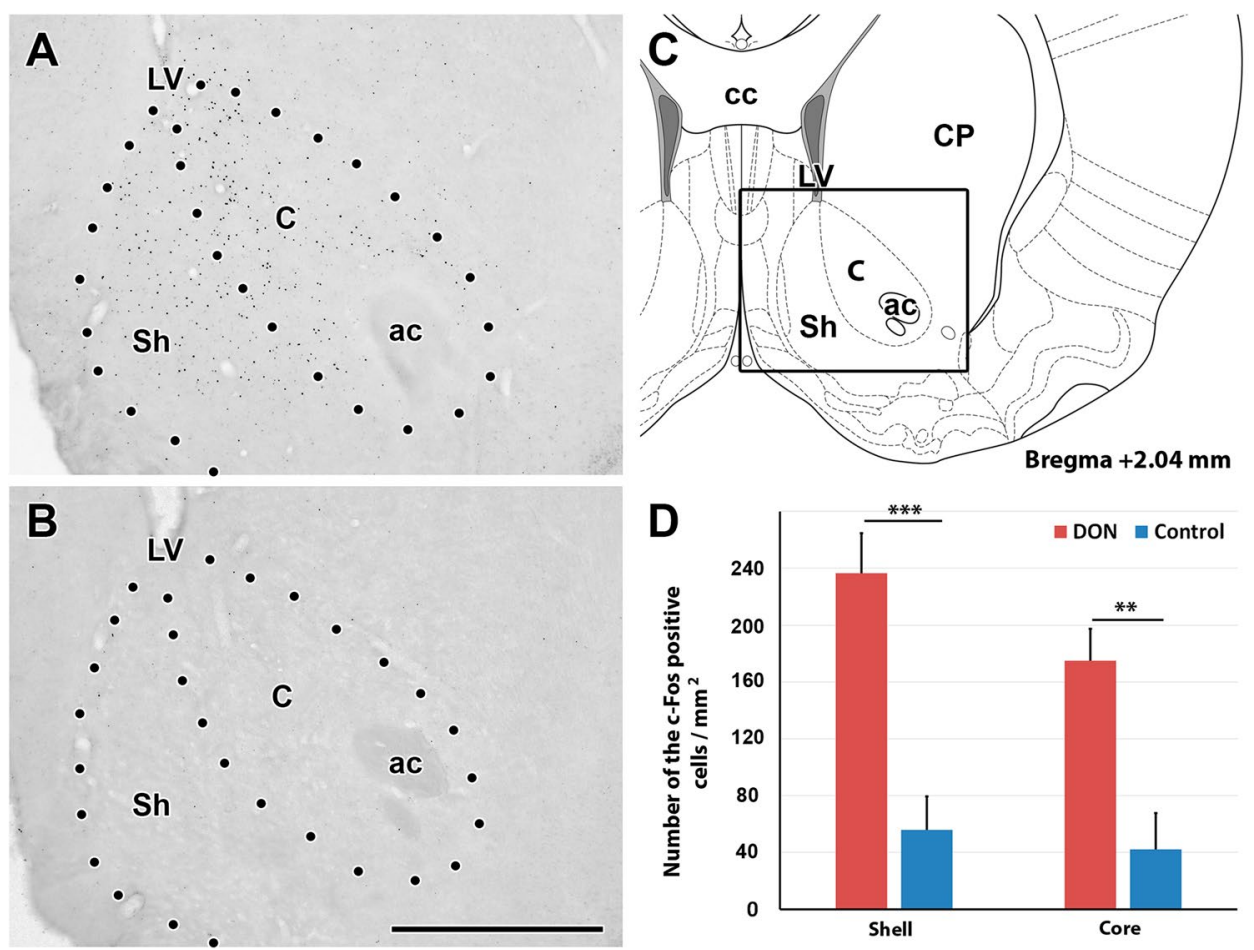

Fig. 4 The distribution and density of c-Fos positive cells are shown in the accumbens nucleus (NAc). a The NAc of a DON injected animal. The black dots represent the c-Fos positive cells. They are located around the anterior commissure (ac) as well as medial to it in both the Core (C) and the Shell (Sh) region of the NAc. b The NAc of control (saline-injected) animal contains only few labelled cells. The scale bar is $1 \mathrm{~mm}$. $\mathbf{c}$ The schematic drawing of a coronal brain section

at bregma level 2.04 frames the field shown in $\mathbf{a}, \mathbf{b}$. $\mathbf{d}$ The density of c-Fos positive cells is shown separately in two different regions of the NAc. The number of c-Fos positive cells in DON injected animals are indicated with red, and the control group are signed with blue. Stars represent significant differences between DON treated and control injected animals $(p=0.01)$. $c c$ corpus callosum, $C P$ caudate putamen, $L V$ lateral ventricle 

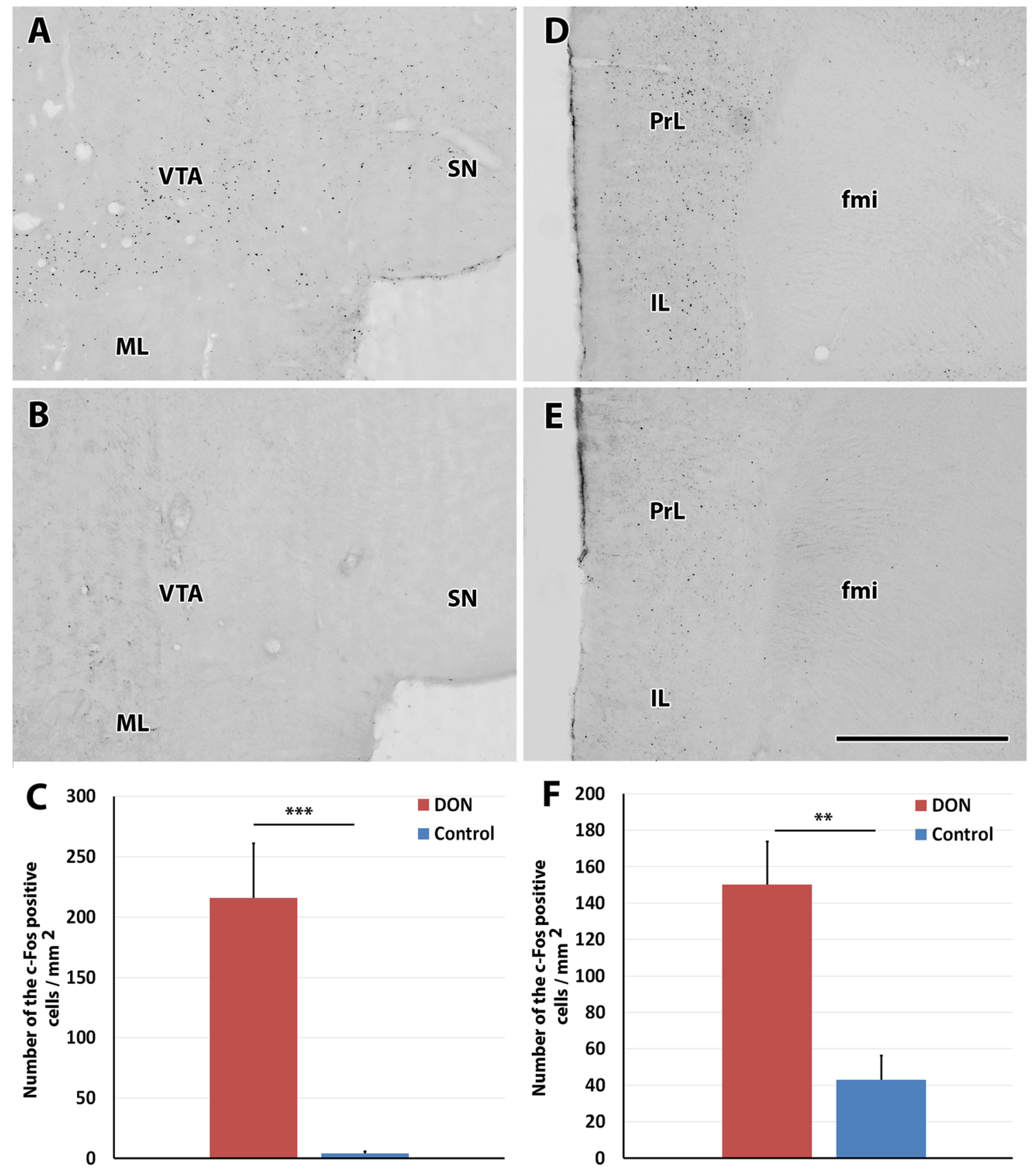

Fig. 5 The presence and quantitative analysis of c-Fos positive cells in the ventral tegmental area and medial prefrontal cortex. a c-Fos positive cells (black dots) are present in the ventral tegmental area (VTA) of a DON injected animal while adjacent brain regions such as the substantia nigra ( $\mathrm{SN})$ and the medial mammillary nucleus (ML) do not contain c-Fos positive neurons. b Photomicrograph of the same field as in A of a control (saline-injected) animal. c-Fos positive neurons are not visible in the VTA. $\mathbf{c}$ The density of c-Fos positive cells in DON-treated (left, red column) and saline injected control animals (right, blue column). d c-Fos positive neurons are abundant in the medial prefrontal cortex of a DON injected animal.

e The medial prefrontal cortex of a control (saline injected) animal contains only a low number of c-Fos positive neurons. $f$ The density of c-Fos positive cells in each animal group in the medial prefrontal cortex. The column representing the number of c-Fos positive cells in DON injected animals is red on the left, while the column of the control group is blue on the right. fmi forceps minor, $I L$ infralimbic cortex, $M L$ medial mammillary nucleus, $P r l$ prelimbic cortex, $S N$ substantia nigra, VTA ventral tegmental area. The 4 histological panels are shown at the same magnification. The scale bar is $1 \mathrm{~mm}$ (colour figure online) 
c-Fos-positive cells were GABAergic (Fig. 6a). Parvalbumin-positive cells were also examined in the NAc where DON-activated neurons did not colocalize with parvalbumin (Fig. 6b).

In the VTA, we counted $264.5 \pm 17.6$ c-Fos-positive cells $/ \mathrm{mm}^{2}$ after acute DON treatment. The number of GABAergic cells in the VTA was $579.7 \pm 46.3$ cells $/ \mathrm{mm}^{2}$. The number of double labelled cells was $231.4 \pm 39.7$ cells $/ \mathrm{mm}^{2}$. On average, $42 \%$ of the GABAergic cells were c-Fos-positive, and $87 \%$ of the c-Fos-positive cells were GABAergic (Fig. 6c). Dopaminergic neurons were visualized with tyrosine-hydroxylase (TH) immunohistochemistry. Labelled cell bodies were present in the VTA while fibres were observed in the NAc and MPFC. After double labelling TH and c-Fos in DON injected animals, c-Fos-positive and TH-positive neurons were both present, however, double labelled cells were not found in the VTA (Fig. 6d).

The density of the c-Fos positive cells is the average of the 4 mice analysed.

\section{The effect of DON on feed intake}

The animals gradually increased their feed intake within the $2 \mathrm{~h}$ when feed was freely available for them (Table 2). Males consumed more feed than females and increased their feed intake to a larger degree from day 1 to 3 .

DON injection affected feed consumption in both males and females as demonstrated by a reduced feed intake on the day of DON injection as compared to the control values in previous and following days. Specifically, the males consumed $14.7 \pm 0.5 \mathrm{~g}$ feed on the 3 rd control day and $17.1 \pm 0.7 \mathrm{~g}$ on the 5th day while they consumed only $12.5 \pm 0.9 \mathrm{~g}$ feed following DON injection (4th day). The male rats who received a saline injection on the 4th day consumed $12.6 \pm 0.7 \mathrm{~g}$ feed on the $3 \mathrm{rd}$ day and $12.8 \pm 1.0 \mathrm{~g}$ on the 5th day. After the saline injection they consumed $12.9 \pm 0.7 \mathrm{~g}$ feed.

The females consumed $10.5 \pm 1.4 \mathrm{~g}$ feed on the control 3rd day and $12.4 \pm 1.0 \mathrm{~g}$ on the 5th day. $5.9 \pm 0.3 \mathrm{~g}$ feed was consumed by them on the day of DON injection (4th day). The females consumed $10.2 \pm 0.7 \mathrm{~g}$ feed on the $3 \mathrm{rd}$ and $10.5 \pm 0.9 \mathrm{~g}$ on the 5 th control day. The female rats
Fig. 6 Phenotypic characterization of DON-activated neurons in the accumbens nucleus (NAc). a Double immunolabeling of GABAergic (green) and c-Fos positive (red) cells in the NAc. b Double immunolabeling of Parvalbumin (green) and c-Fos positive (red) cells in the NAc. $\mathbf{c}$ The double immunolabeling of GABAergic (green) and c-Fos positive (red) cells in the ventral tegmental area. d A high magnification of the ventral tegmental area about TH (green) and c-Fos (red) cells. The scale bar is $50 \mu \mathrm{m}$ in $\mathbf{a}, \mathbf{b}$ images, $25 \mu \mathrm{m}$ in $\mathbf{c}, \mathbf{d}$ images. Arrows in c, $\mathbf{d}$ show colocalization of GABA and c-Fos (colour figure online)
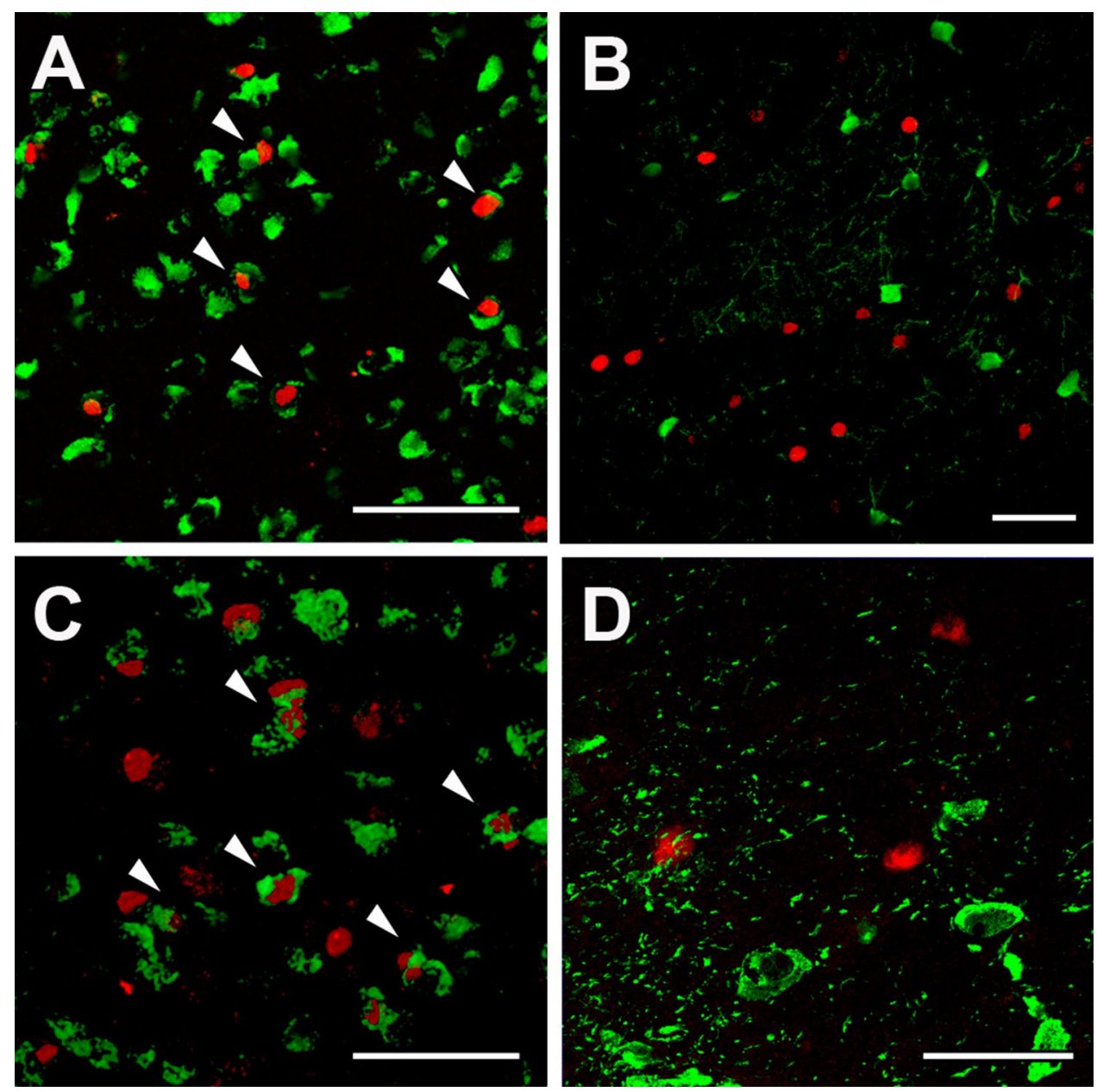
Table 2 The measured weights of the rats in the beginning of the experiment and the amount of consumed feed on each day during the experiment

\begin{tabular}{|c|c|c|c|c|c|c|c|c|}
\hline \multirow[t]{2}{*}{ Number of rat } & \multirow[t]{2}{*}{ Sex } & \multirow{2}{*}{$\begin{array}{l}\text { Treatment on } \\
\text { the } 4 \text { th day }\end{array}$} & \multirow{2}{*}{$\begin{array}{l}\text { Body } \\
\text { weight (g) }\end{array}$} & \multicolumn{5}{|c|}{ Consumed food (g) } \\
\hline & & & & Day 1 & Day 2 & Day 3 & Day 4 & Day 5 \\
\hline 1 & o & DON & 237 & 5 & 9 & 7 & 6 & 15 \\
\hline 2 & q & DON & 204 & 6 & 7 & 8 & 5 & 9 \\
\hline 3 & q & DON & 209 & 4 & 6.5 & 6 & 6 & 10 \\
\hline 4 & q & DON & 233 & 5 & 8 & 8 & 7 & 11 \\
\hline 5 & q & DON & 236 & 2 & 8 & 10 & 4 & 13 \\
\hline 6 & q & DON & 208 & 9 & 13 & 20.3 & 5.8 & 19.8 \\
\hline 7 & 우 & DON & 170 & 6 & 9.3 & 10 & 5.1 & 11.5 \\
\hline 8 & 우 & DON & 179 & 4 & 6.3 & 8.3 & 7 & 12.2 \\
\hline 9 & q & DON & 175 & 4 & 7 & 10.5 & 7.5 & 10.8 \\
\hline 10 & q & DON & 215 & 14 & 18.5 & 16.5 & 5.8 & 12 \\
\hline 11 & 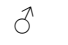 & DON & 224 & 8 & 12.5 & 15 & 12 & 18 \\
\hline 12 & $\hat{\sigma}$ & DON & 191 & 7 & 11 & 16 & 14 & 18 \\
\hline 13 & $\hat{0}$ & DON & 208 & 6 & 12 & 16 & 16 & 18 \\
\hline 14 & $\hat{\jmath}$ & DON & 229 & 11 & 12 & 16 & 15 & 17 \\
\hline 15 & $\hat{\sigma}$ & DON & 194 & 9 & 11 & 12 & 15 & 15 \\
\hline 16 & $0^{2}$ & DON & 270 & 11.3 & 12.8 & 13.5 & 9 & 20 \\
\hline 17 & $\hat{0}$ & DON & 277 & 14 & 19 & 13.8 & 11.8 & 19.2 \\
\hline 18 & $\hat{\sigma}$ & DON & 307 & 10 & 12.5 & 15 & 10.3 & 14 \\
\hline 19 & 0 & DON & 277 & 7.1 & 6.9 & 12.8 & 7 & 13.7 \\
\hline 20 & $\hat{\sigma}$ & DON & 270 & 7.7 & 11.9 & 17 & 14.5 & 18 \\
\hline 21 & 우 & Saline & 229 & 5 & 10 & 10 & 9 & 7.5 \\
\hline 22 & q & Saline & 192 & 3 & 9 & 9 & 8 & 9 \\
\hline 23 & 우 & Saline & 224 & 6 & 10 & 12 & 10 & 13 \\
\hline 24 & q & Saline & 208 & 3 & 9 & 8 & 10 & 10 \\
\hline 25 & q & Saline & 202 & 8 & 7 & 7 & 7 & 7 \\
\hline 26 & q & Saline & 254 & 6 & 11.5 & 14.3 & 12 & 14 \\
\hline 27 & 우 & Saline & 237 & 4.2 & 8.2 & 9 & 12.5 & 7 \\
\hline 28 & q & Saline & 245 & 5.6 & 9.7 & 10.5 & 11.6 & 13.2 \\
\hline 29 & q & Saline & 246 & 3.7 & 10.8 & 13 & 10 & 12.9 \\
\hline 30 & q & Saline & 247 & 8.2 & 10.5 & 12.3 & 11.1 & 13.6 \\
\hline 31 & 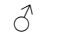 & Saline & 361 & 7 & 6 & 10 & 11 & 12 \\
\hline 32 & $\sigma^{\lambda}$ & Saline & 314 & 8 & 9.5 & 10 & 12 & 13 \\
\hline 33 & $\hat{0}$ & Saline & 217 & 7 & 11 & 13 & 14 & 13 \\
\hline 34 & 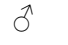 & Saline & 202 & 6 & 11 & 13 & 12 & 10 \\
\hline 35 & $\hat{\sigma}$ & Saline & 240 & 7 & 12 & 14 & 15 & 17 \\
\hline 36 & 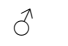 & Saline & 267 & 10.7 & 11.6 & 18.3 & 15.2 & 20.1 \\
\hline 37 & $\hat{0}$ & Saline & 201 & 8 & 9.8 & 13.4 & 14.5 & 10.2 \\
\hline 38 & $\hat{\sigma}$ & Saline & 235 & 7.3 & 7.8 & 12.3 & 14.9 & 11.9 \\
\hline 39 & $\hat{\sigma}$ & Saline & 216 & 8.3 & 10.5 & 12.9 & 14.2 & 10.7 \\
\hline 40 & $\hat{\sigma}$ & Saline & 187 & 8.9 & 8.2 & 9.3 & 8 & 9 \\
\hline
\end{tabular}

consumed $10.1 \pm 0.5 \mathrm{~g}$ feed after the saline injection on the 4th day. We expressed the data in relative feed intake to body weight (Fig. 7). According to the result of the 2-way Repeated Measure ANOVA test, DON treatment had a significant effect on the feed intake $(\mathrm{F} 2.36)=31.63$, $p<0.0001)$. The saline injection did not have a significant effect on the feed intake $(F(2.36)=0.23, p=0.8)$. Based on Tukey's test, significant differences were found both for the males $(p<0.01)$ and the females $(p<0.0001)$ in response to DON treatment (day 4) while feed intake in the previous and following days (days 3 and 5) did not differ from each other in either sex. The saline injection did not cause changes between the days or the sexes.

Taken together, our data indicated that acute DON treatment in a dose of $1 \mathrm{mg} / \mathrm{kg}$ bw decreased the feed intake in both male and female rats. 


\section{A DON treatment}

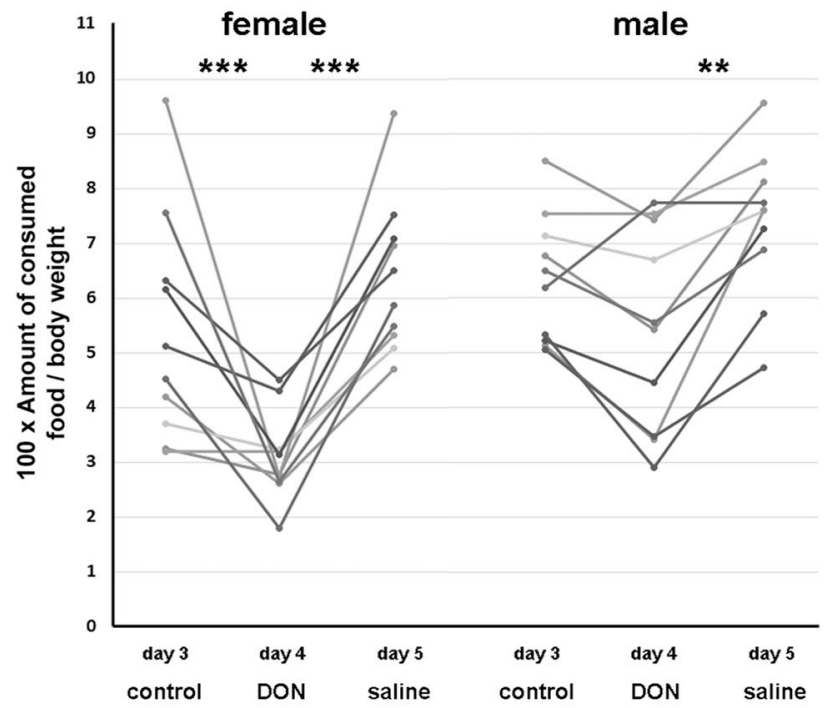

\section{B saline treatment}

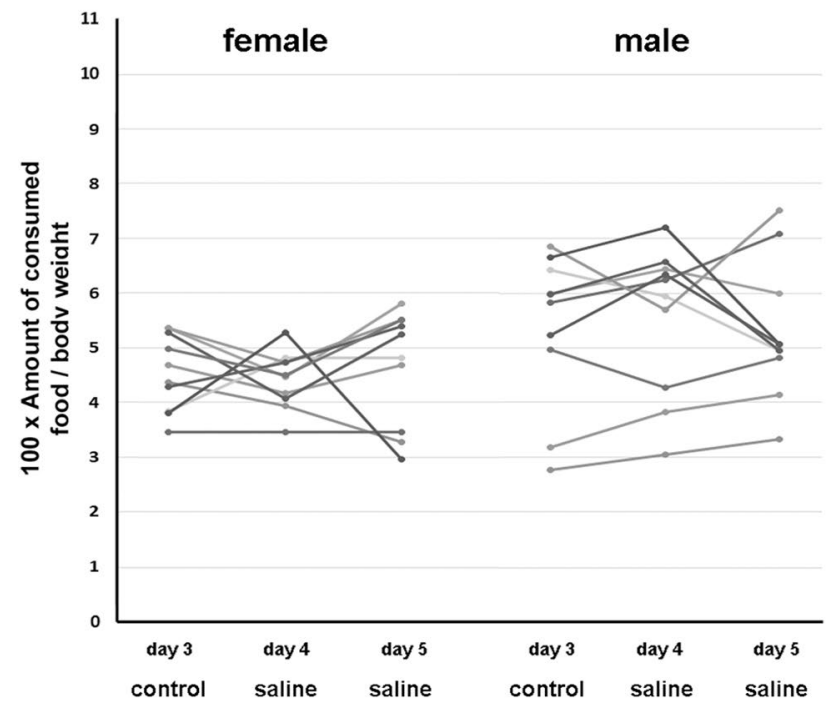

Fig. 7 The effect of DON on feed intake in male and female after DON or saline injection. The amount of feed consumed within the $2 \mathrm{~h}$ feeding period relative to body weight is shown on the 3rd control day, following DON injection (a) or saline injection (b) on the 4th day, and following saline injection on the 5th day. DON reduced feed intake in both males and females on the 4th day after DON injection but not after saline injection

\section{The effect of DON on spontaneous maternal behaviour}

The control group of mothers (which received saline injection the following day) spent $81.0 \pm 13.7 \%$ of their time with suckling while the treated group (which received DON injection the following day) spent $83.7 \pm 8.9 \%$ with suckling on the first day. On the second day, the control group suckled the pups in $93.3 \pm 6.6 \%$ of their time. In turn, the treated group spent only $13.1 \pm 23.4 \%$ of their time with suckling, which is a dramatic decrease (Fig. 8a).

When mothers were not suckling, they typically explored the cage outside of the nest (DON 2nd day: $59.24 \%$; Control 2nd day: $2.72 \%$ ). In a small percentage of their time, the mothers also groomed the pups (DON: $0.65 \%$; control: $0.08 \%$ ), and they were in the nest without suckling (DON: 9.69\%, control: 5.65\%) (Fig. 8b). Based on Bonferroni's multiple comparisons test, DON had a significant effect on the exploration and the suckling behaviour $(p<0.05)$.

\section{Pup retrieval}

When pups were placed into corners of the cage other than where the nest was located, as expected, the mothers took the pups to their mouth and carried them back to the nest. At 30 min following the injection of DON, no changes appeared in the pup retrieval behaviour of the mothers as the latencies to carry back the pups did not change as compared to the previous day latencies. In contrast, a robust effect was found at 60 min following the drug injection. On the 1st day, when both of the animal groups (DON and control) received saline injection, the pup retrieval time of the 2 groups were $18.8 \pm 9.3 \mathrm{~s}$ and $64.7 \pm 20.2 \mathrm{~s}$ at the 1 st pup, $44.5 \pm 9.3 \mathrm{~s}$ and $97.8 \pm 29.7 \mathrm{~s}$ at the $3 \mathrm{rd}$ pup and $85.3 \pm 21.6 \mathrm{~s}$ and $194.3 \pm 39.3 \mathrm{~s}$ at the 10th pup, respectively. On the 2nd day, when they were administered saline or DON, respectively, the control animal group took the first pup back to the nest with a latency of $70.7 \pm 22.6 \mathrm{~s}$, which represents a $109.3 \%$ related to the retrieval time on the previous day. Taking the third pup to the nest needed $114.6 \pm 20.2 \mathrm{~s}$, which is $117.1 \%$ the retrieval time shown in the previous day value in the control animals. Carrying back the last pup (10th) to the nest, the control group took $201.9 \pm 42.7$ s, which is $103.9 \%$ of their time in percentage of the previous day latency. The DON injected group took the 1st pup back to the nest $228.3 \pm 54.5 \mathrm{~s}$, which is a $1214.4 \%$ increase compared to the previous day latencies (Fig. 8c). Following DON treatment, they retrieved the 3rd pup in $230.7 \pm .53 .6 \mathrm{~s}$, which is $518.2 \%$ higher than their saline day performance. They took back the last pup into the nest in $235.9 \mathrm{~s}$ on the second day, which was a $276.7 \%$ increase compared to their previous control day. So, the mothers, who received DON, took significantly longer to take back the pups to the nest than when they received control saline injection based on two-way repeated measure ANOVA $(F(1,4)=11.97$. Sidak' multiple comparison test further demonstrated that the effect of DON was significant on each day. In contrast, the repeated saline injection did not have a significant effect $(F(1,4)=0.2705)$. 
Fig. 8 The effect of DON on maternal care. a The percentage of the total time the control (saline-injected) and the DON injected animals spent with suckling in the tested $60 \mathrm{~min}$ following the return of the pups after 1-h separation from them. On the first day, each group received saline injection and spent a similarly large percentage of their time with suckling. On the second day, saline (blue) or DON (red) was administered to the 2 groups of animals. DON injection markedly reduced the time spent with suckling as compared to the control group as well as to previous day self-control data. b The illustration shows how the control and DON-treated animals behaved during the test period. It is visible that the time DON injected animals saved with reduced suckling time was spent mostly with exploration. c The results of the pup retrieval tests (first, third and last pup) are shown in a way that data from individual animals can be appreciated. Data points of the same animals are shown with the same colour in both the DON treated and the control group. Furthermore, data points for the withdrawal time of the same number of pups (first, third or last) are connected with lines. The latency to take back the pups to the nest was significantly increased as compared to previous day control values of the same animals in response to DON injection (upper panels) whereas the latency of withdrawal was not changed between the first and second day in the group where the rats received saline injection both days (lower panel)

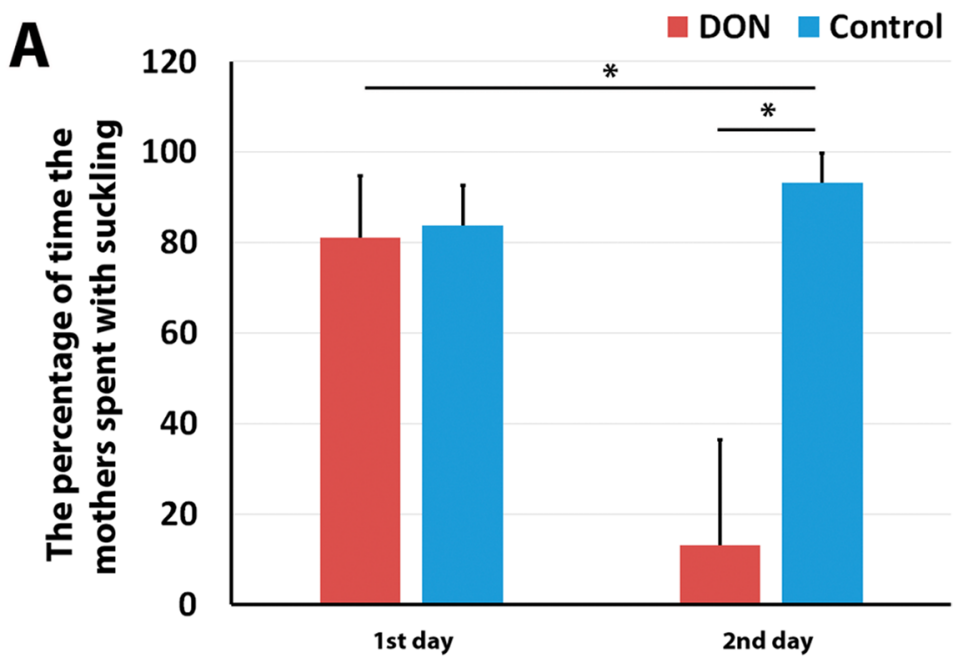

B

Day 2, saline injection

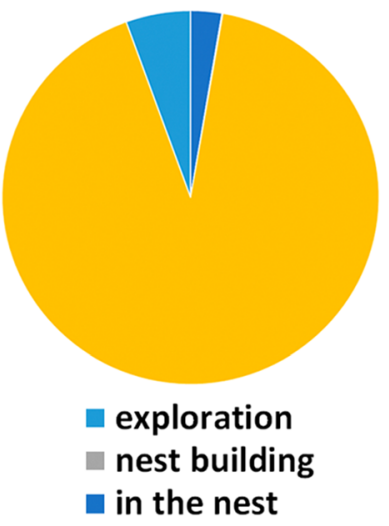

Day 2, DON injection

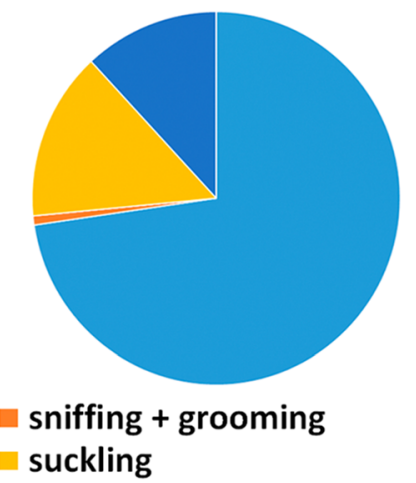

third pup

last (10th) pup

DON treated group
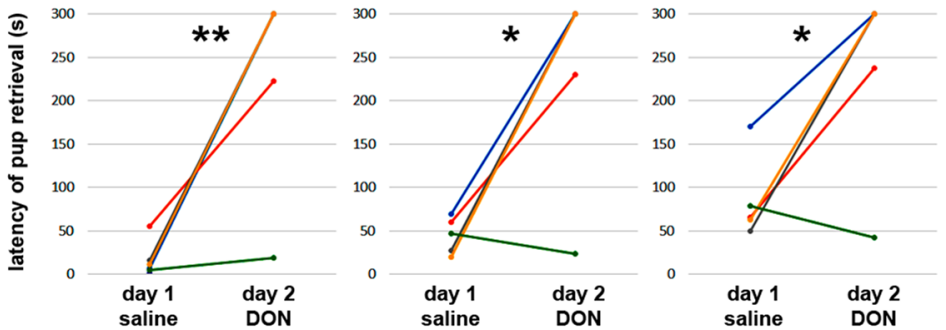

Control group
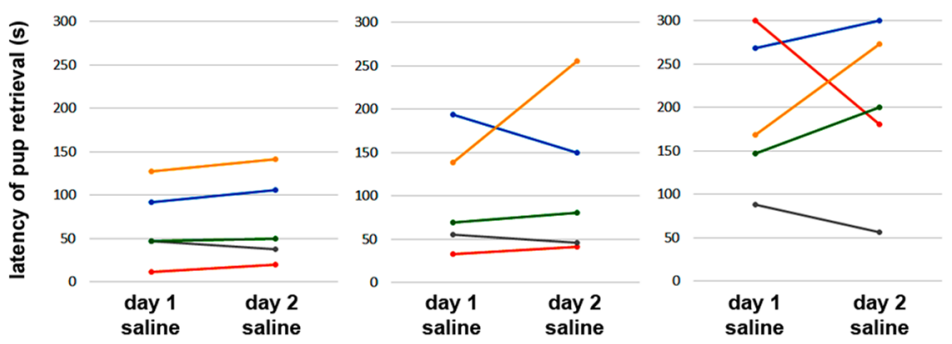


\section{DON treatment did not induce conditioned place preference}

After the 3-day training period, when the rats received daily DON injections in the DON-associated cage while control saline injections in the control cage, the animals had a free option to stay in the DON-associated or the saline-associated cage on the test day (day 4). The males spent $51.7 \pm 9.6 \%$ of their time in the DON-associated cage, and $48.1 \pm 3.3 \%$ of their time in the saline-associated cage. The females spent $45.5 \pm 34.0 \%$ of their time in the DON-associated cage and $54.5 \pm 34 \%$ of their time in the control cage. Thus, there was no significant difference between the time the animals spent in the 2 cages in either the males or females (Student's $t$ tests).

\section{Discussion}

\section{Activation of the brain by DON}

DON-induced c-Fos expression was described in 2 species, rats and mice. Both exhibited similar degree and distribution of c-Fos immunoreactivity following acute intraperitoneal injection of DON (1 mg/kg bw) resulted in c-Fos labelling $2 \mathrm{~h}$ after its administration. In contrast, the number of c-Fos positive cells remained low following control injections suggesting specific drug actions in response to DON administration. It is known that the appearance of c-Fos protein takes about an hour following stimulation of neurons, after which c-Fos remains in the cell for a few hours (Herrera and Robertson 1996). So, DON may have reached and affected its targets within an hour. Previous data suggest that the penetration of DON to the brain is species dependent (Chen et al. 2017; Payros et al. 2016). DON concentrations in the brain reach a maximum after 5-10 $\mathrm{min}$ in sheep and 30-60 min in swine (Pestka 2008). In line with these data, the effect of DON on pup retrieval was not seen after 30 min but only after 60 min following i.p. administration of the drug.

Despite the systemic administration of DON, only a few brain regions demonstrated c-Fos expression. Based on the characteristics of the c-Fos technique, it is possible that some activated neurons remained unrevealed following DON injection as some neurons can be activated without the appearance of c-Fos protein (Perez-Cadahia et al. 2011). Still, the finding that most brain regions did not contain c-Fos immunoreactivity argues against a non-specific action of DON, e.g. a general neurotoxic action via the previously revealed ribosomal mechanism (Pestka 2010) to evoke c-Fos activity. Since neither sensory nor circumventricular centres showed activation by DON in our study, it is likely that DON exerted a direct effect on the c-Fos positive neurons rather than activating them from the periphery through indirect neuronal pathways, e.g. via its effect on the immune system or the intestine (Pestka 2010). DON is known to penetrate the blood-brain barrier (Behrens et al. 2015; Payros et al. 2016; Pestka et al. 2008), which allows a direct effect on its brain targets. The specificity of DON action is also supported by the finding that even within the affected brain regions, only a subset of neurons was activated. Interestingly, the activated neurons were mainly located in brain regions belonging to the reward system. Previously, the activation of only some of these brain areas, such as the accumbens nucleus was reported in response to prolonged application of DON in low dose $(100 \mu \mathrm{g} / \mathrm{kg}$ bw) or higher acute dose $(12.5 \mathrm{mg} / \mathrm{kg}$ bw) (Faeste et al. 2019). We demonstrated that $1 \mathrm{mg} / \mathrm{kg}$ bw acute injection of DON can also evoke activation of the NAc and that the increase in the neuronal activity takes place in both the core and the shell subdivisions of the nucleus. We also found similarities with previous c-Fos studies in the paraventricular thalamic nucleus reported to be activated by low dose chronic and high dose acute DON (Faeste et al. 2019). The paraventricular thalamic nucleus was also activated in a previous pig study (Gaige et al. 2013) after $1 \mathrm{mg} / \mathrm{kg}$ bw per os DON application. A substantial amount of c-Fos positive cells were found in the paraventricular thalamic nucleus following saline injection, too. It could be a consequence of the stress factor of the injection itself although it is also possible that the paraventricular thalamic nucleus contains c-Fos positive neurons in the absence of experimental stimulus. Furthermore, the number of c-Fos positive neurons seemed to be slightly increased following acute DON injection. However, the extent of the increase did not seem to be as large as in the accumbens nucleus. In addition, the present study revealed additional brain sites of activation, such as the medial prefrontal cortex and the ventral tegmental area, and thus, demonstrated a different activation pattern by acute DON administration. Our findings were similar to the pigs in some other brain regions, too, including the amygdala, and the lateral hypothalamic area. In turn, the area postrema and the nucleus of the solitary tract, brain sites involved in conditioned taste aversion, and vomiting previously reported to be activated by DON in the pigs (Gaige et al. 2013) were not affected in the present study. These differences may be explained by the lower concentration of DON applied in our study, the different mechanisms between activation following acute and chronic administration, and species differences, particularly that pigs are more sensitive to the toxin (Andretta et al. 2012).

\section{Behavioural consequences of acute DON injection}

The reward system, which was activated by DON, plays an outstanding role in the control of goal-directed behaviours (Dulac et al. 2014), so the effect of DON on two such behaviours was investigated. In the applied feeding 
protocol, daily feed intake is confined to $2 \mathrm{~h}$, which allows the examination of the effect of DON injection on feed intake as the feeding pattern is predictable due to the restricted availability of the feed (Fuller and Snoddy 1968) when DON concentration is the maximal. Chronic DON administration has been reported to inhibit feed intake in different species (Wu et al. 2014) including the pig (Pierron et al. 2016; Wu et al. 2014). Here, we demonstrated an inhibitory effect of acute DON injection using the restricted feed availability protocol in the rat. We also provided evidence that DON was not aversive to the animals since it did not create a negative place preference. If the toxin-induced a taste aversion in the rats, the cage with saline would be chosen. c-Fos immunoreactivity following an acute high-dose DON administration showed increased c-Fos expression in the anorexigenic circuit (Faeste et al. 2019). The lack of c-Fos activation in the dorsal vagal complex, a vomiting centre including the circumventricular organ area postrema, the nucleus of the solitary tract, and the motor nucleus of the vagal nerve argue against nausea-inducing action of DON at the low concentration applied throughout our study. Most importantly, however, the feed intake was normal a day following DON administration suggesting that conditioned taste aversion did not take place and DON inhibits feeding behaviour probably via reducing the perceived reward value of the feed. This conclusion is also supported by the finding that (1) the control animals did not show any changes in their feed intake and (2) no place preference was induced by DON administration. In a previous study, the weight reduction of female Swiss mice was significant by oral administration of $45 \mu \mathrm{g}$ DON $/ \mathrm{kg}$ bw/day for 7 days (Kouadio et al. 2013), which is consistent with our findings on reduced feed intake. Therefore, the effect of DON on another, this time female-specific reward-driven behaviour, maternal behaviour was also examined. DON exhibited a dramatic effect on spontaneous maternal behaviour as the time spent with suckling was markedly reduced in mother rats after DON injection. Furthermore, DON was also strongly inhibitory in an induced maternal behaviour, the pup retrieval, which is the most often used test of maternal motivation (Bridges 2015). The increased pup retrieval latencies suggest that DON reduces maternal motivation, which may have been the underlying reason of the reduced suckling behaviour, too. The maternal behavioural effects of DON have not been investigated previously. However, DON showed limited effect of sow health and production despite a reduction in feed consumption (Sayyari et al. 2018). Apart from species differences, it is possible that raising a piglet in a farm does not represent a challenging environment for maternal motivations, therefore, such an effect of DON could have stayed hidden in the absence of specific tests on it.

\section{Potential mechanisms of the behavioural actions}

Since two different reward-driven behaviours were affected by DON treatment, and neurons in the reward system of the brain were activated, it seems likely that general rewardrelated rather than behaviour-specific brain mechanisms are involved in the effect of DON. Even though neurons in the NAc were activated by DON, its addictive actions are not expected as its administration did not induce place preference. We used tyrosine hydroxylase (TH) as a marker of dopaminergic neurons (Molinoff and Axelrod 1971) and found the same distribution of TH as described previously (Bjorklund and Dunnett 2007). However, dopaminergic neurons were not activated based on double labelling experiments. Instead, some GABAergic neurons showed c-Fos expression suggesting that they may mediate the actions of DON on the reward-driven behaviours. The reduced motivation may actually be related to decreased dopamine level, which has been reported following acute low dose DON injection (Bonnet et al. 2012; Prelusky et al. 1992).

It is also noteworthy to mention that we described a unique way of specifically activating some GABAergic neurons without dopaminergic activation in the reward system. Importantly, GABAergic neurons in other brain regions are not affected, which results in an experimental tool potentially useful for further studies investigating the reward system.

\section{Conclusions}

While the actions of DON on peripheral organs and tissues is well documented, data on its effects in the brain are less abundant. In the present study, we examined the potential neurotoxicity of DON by investigating the neuronal activation pattern following its intraperitoneal injection to adult male rats at a dose of $1 \mathrm{mg} / \mathrm{kg}$ bw. Activation was particularly high in reward centres. In contrast, we did not find neuronal activation in vomiting centres or dependency to the saline injection into the conditioned place preference test. Furthermore, DON did not evoke taste aversion. In turn, we detected reduced motivated behaviours, both feeding and maternal behaviours following DON injection suggesting that DON may have an inhibitory effect on motivated behaviours in addition to its previously reported toxic actions. The more profound effect of DON on feed intake in females, as well as the dramatic effect of DON on the maternal behaviours suggest that the drug might have sexually dimorphic action: DON exposure may have more serious consequences in females. The results also point to the importance of the reproductive status regarding the effects of DON. It is typically not investigated for DON toxicology, but the toxin may have a specific effect on mothers. Therefore, special 
attention should be given to DON intoxication during pregnancy and the postpartum period.

Acknowledgements Open access funding provided by Eötvös Loránd University (ELTE). The work was supported by the National Research, Development and Innovation Office-the NKFIH NVKP_16-1-20160016, NKFIH-4300-1/2017-NKP_17, the NKFIH-2920-1/2016VEKOP-2.3.-15, the NKFIH-6785-1/2016-VEKOP-2.3.3-15, NKFIH OTKA K116538, NKFIH OTKA K134221, the Eötvös Loránd University Institutional Excellence Program NKFIH-1157-8/2019-DT, and the New National Excellence Program of the Ministry of Human Capacities Research Grant ÚNKP-16-3.

\section{Compliance with ethical standards}

Ethics approval This article does not contain clinical studies or patient data. This article does not contain any studies with human participants performed by any of the authors. All applicable international, national, and/or institutional guidelines for the care and use of animals were followed. All procedures performed in studies involving animals were in accordance with the ethical standards of the institution at which the studies were conducted.

Conflict of interest The authors declare that they have no conflict of interest.

Open Access This article is licensed under a Creative Commons Attribution 4.0 International License, which permits use, sharing, adaptation, distribution and reproduction in any medium or format, as long as you give appropriate credit to the original author(s) and the source, provide a link to the Creative Commons licence, and indicate if changes were made. The images or other third party material in this article are included in the article's Creative Commons licence, unless indicated otherwise in a credit line to the material. If material is not included in the article's Creative Commons licence and your intended use is not permitted by statutory regulation or exceeds the permitted use, you will need to obtain permission directly from the copyright holder. To view a copy of this licence, visit http://creativecommons.org/licenses/by/4.0/.

\section{References}

Al-Hazmi MA, Rawi SM, Arafa NM, Wagas A, Montasser AO (2015) The potent effects of ginseng root extract and memantine on cognitive dysfunction in male albino rats. Toxicol Ind Health 31(6):494-509. https://doi.org/10.1177/0748233713475517

Andretta I, Kipper M, Lehnen CR, Hauschild L, Vale MM, Lovatto PA (2012) Meta-analytical study of productive and nutritional interactions of mycotoxins in growing pigs. Animal 6(9):1476-1482. https://doi.org/10.1017/S1751731111002278

Awad W, Ghareeb K, Bohm J, Zentek J (2013) The toxicological impacts of the Fusarium mycotoxin, deoxynivalenol, in poultry flocks with special reference to immunotoxicity. Toxins (Basel) 5(5):912-925. https://doi.org/10.3390/toxins5050912

Behrens M, Huwel S, Galla HJ, Humpf HU (2015) Blood-brain barrier effects of the fusarium mycotoxins deoxynivalenol, 3 acetyldeoxynivalenol, and moniliformin and their transfer to the brain. PLoS ONE 10(11):e0143640. https://doi.org/10.1371/journ al.pone. 0143640

Bjorklund A, Dunnett SB (2007) Dopamine neuron systems in the brain: an update. Trends Neurosci 30(5):194-202. https://doi. org/10.1016/j.tins.2007.03.006
Bonnet MS, Roux J, Mounien L, Dallaporta M, Troadec JD (2012) Advances in deoxynivalenol toxicity mechanisms: the brain as a target. Toxins (Basel) 4(11):1120-1138. https://doi.org/10.3390/ toxins 4111120

Bridges RS (2015) Neuroendocrine regulation of maternal behavior. Front Neuroendocrinol 36:178-196. https://doi.org/10.1016/j. yfrne.2014.11.007

Chen SS, Li YH, Lin MF (2017) Chronic exposure to the fusarium mycotoxin deoxynivalenol: impact on performance, immune organ, and intestinal integrity of slow-growing chickens. Toxins (Basel) 9:10. https://doi.org/10.3390/toxins9100334

Cohen JY, Haesler S, Vong L, Lowell BB, Uchida N (2012) Neurontype-specific signals for reward and punishment in the ventral tegmental area. Nature 482(7383):85-88. https://doi.org/10.1038/ nature 10754

Cservenak M, Szabo ER, Bodnar I et al (2013) Thalamic neuropeptide mediating the effects of nursing on lactation and maternal motivation. Psychoneuroendocrinology 38(12):3070-3084. https://doi.org/10.1016/j.psyneuen.2013.09.004

Cunningham CL, Gremel CM, Groblewski PA (2006) Drug-induced conditioned place preference and aversion in mice. Nat Protoc 1(4):1662-1670. https://doi.org/10.1038/nprot.2006.279

Dulac C, O'Connell LA, Wu Z (2014) Neural control of maternal and paternal behaviors. Science 345(6198):765-770. https://doi. org/10.1126/science.1253291

Faeste CK, Pierre F, Ivanova L, Sayyari A, Massotte D (2019) Behavioural and metabolomic changes from chronic dietary exposure to low-level deoxynivalenol reveal impact on mouse well-being. Arch Toxicol 93(7):2087-2102. https://doi.org/10.1007/s0020 4-019-02470-1

Franklin KBJ, Paxinos G (1997) The mouse brain in stereotaxic coordinates. Academic Press, San Diego

Fuller RW, Snoddy HD (1968) Feeding schedule alteration of daily rhythm in tyrosine alpha-ketoglutarate transaminase of rat liver. Science 159(3816):738. https://doi.org/10.1126/scien ce. 159.3816 .738

Gaige S, Bonnet MS, Tardivel C et al (2013) c-Fos immunoreactivity in the pig brain following deoxynivalenol intoxication: focus on NUCB2/nesfatin-1 expressing neurons. Neurotoxicology 34:135-149. https://doi.org/10.1016/j.neuro.2012.10.020

Girardet C, Bonnet MS, Jdir R et al (2011a) Central inflammation and sickness-like behavior induced by the food contaminant deoxynivalenol: a PGE2-independent mechanism. Toxicol Sci 124(1):179-191. https://doi.org/10.1093/toxsci/kfr219

Girardet C, Bonnet MS, Jdir R et al (2011b) The food-contaminant deoxynivalenol modifies eating by targeting anorexigenic neurocircuitry. PLoS ONE 6(10):e26134. https://doi.org/10.1371/ journal.pone.0026134

Herrera DG, Robertson HA (1996) Activation of c-fos in the brain. Prog Neurobiol 50(2-3):83-107. https://doi.org/10.1016/s0301 -0082(96)00021-4

Hughes DM, Gahl MJ, Graham CH, Grieb SL (1999) Overt signs of toxicity to dogs and cats of dietary deoxynivalenol. J Anim Sci 77(3):693-700. https://doi.org/10.2527/1999.773693x

Kardos J, Dobolyi A, Szabo Z et al (2019) Molecular plasticity of the nucleus accumbens revisited-astrocytic waves shall rise. Mol Neurobiol. https://doi.org/10.1007/s12035-019-1641-z

Kelley AE, Berridge KC (2002) The neuroscience of natural rewards: relevance to addictive drugs. J Neurosci 22(9):3306-3311

Kouadio JH, Moukha S, Brou K, Gnakri D (2013) Lipid metabolism disorders, lymphocytes cells death, and renal toxicity induced by very low levels of deoxynivalenol and fumonisin b1 alone or in combination following 7 days oral administration to mice. Toxicol Int 20(3):218-223. https://doi.org/10.4103/09716580.121673 
Lebrun B, Tardivel C, Felix B et al (2015) Dysregulation of energy balance by trichothecene mycotoxins: mechanisms and prospects. Neurotoxicology 49:15-27. https://doi.org/10.1016/j.neuro 2015.04.009

Leko AH, Cservenak M, Szabo ER, Hanics J, Alpar A, Dobolyi A (2017) Insulin-like growth factor I and its binding protein-3 are regulators of lactation and maternal responsiveness. Sci Rep 7(1):3396. https://doi.org/10.1038/s41598-017-03645-5

Li Z, Chen Z, Fan G, Li A, Yuan J, Xu T (2018) Cell-type-specific afferent innervation of the nucleus accumbens core and shell. Front Neuroanat 12:84. https://doi.org/10.3389/fnana.2018.00084

Matsumoto M, Hikosaka O (2009) Two types of dopamine neuron distinctly convey positive and negative motivational signals. Nature 459(7248):837-841. https://doi.org/10.1038/nature08028

McIntire SL, Reimer RJ, Schuske K, Edwards RH, Jorgensen EM (1997) Identification and characterization of the vesicular GABA transporter. Nature 389(6653):870-876. https://doi. org/10.1038/39908

Molinoff PB, Axelrod J (1971) Biochemistry of catecholamines. Annu Rev Biochem 40:465-500. https://doi.org/10.1146/annur ev.bi.40.070171.002341

Ngampongsa S, Ito K, Kuwahara M, Kumagai S, Tsubone H (2011) Arrhythmias and alterations in autonomic nervous function induced by deoxynivalenol (DON) in unrestrained rats. $\mathrm{J}$ Toxicol Sci 36(4):453-460. https://doi.org/10.2131/jts.36.453

Olah S, Cservenak M, Keller D et al (2018) Prolactin-induced and neuronal activation in the brain of mother mice. Brain Struct Funct 223(7):3229-3250. https://doi.org/10.1007/s00429-018-1686-1

Olazabal DE, Pereira M, Agrati D et al (2013) New theoretical and experimental approaches on maternal motivation in mammals. Neurosci Biobehav Rev 37(8):1860-1874. https://doi. org/10.1016/j.neubiorev.2013.04.003

Paxinos G, Watson C (2005) The Rat Brain in Stereotaxic Coordinates. Academic Press, San Diego

Payros D, Alassane-Kpembi I, Pierron A, Loiseau N, Pinton P, Oswald IP (2016) Toxicology of deoxynivalenol and its acetylated and modified forms. Arch Toxicol 90(12):2931-2957. https://doi. org/10.1007/s00204-016-1826-4

Peng Z, Chen L, Xiao J et al (2017) Review of mechanisms of deoxynivalenol-induced anorexia: the role of gut microbiota. J Appl Toxicol 37(9):1021-1029. https://doi.org/10.1002/jat.3475

Perez-Cadahia B, Drobic B, Davie JR (2011) Activation and function of immediate-early genes in the nervous system. Biochem Cell Biol 89(1):61-73. https://doi.org/10.1139/O10-138

Pestka JJ (2003) Deoxynivalenol-induced IgA production and IgA nephropathy-aberrant mucosal immune response with systemic repercussions. Toxicol Lett 140-141:287-295. https://doi. org/10.1016/s0378-4274(03)00024-9

Pestka JJ (2008) Mechanisms of deoxynivalenol-induced gene expression and apoptosis. Food Addit Contam Part A Chem Anal Control Expo Risk Assess 25(9):1128-1140

Pestka JJ (2010) Deoxynivalenol: mechanisms of action, human exposure, and toxicological relevance. Arch Toxicol 84(9):663-679. https://doi.org/10.1007/s00204-010-0579-8
Pestka JJ, Islam Z, Amuzie CJ (2008) Immunochemical assessment of deoxynivalenol tissue distribution following oral exposure in the mouse. Toxicol Lett 178(2):83-87. https://doi.org/10.1016/j. toxlet.2008.02.005

Pierron A, Alassane-Kpembi I, Oswald IP (2016) Impact of two mycotoxins deoxynivalenol and fumonisin on pig intestinal health. Porcine Health Manag 2:21. https://doi.org/10.1186/s4081 3-016-0041-2

Prelusky DB, Yeung JM, Thompson BK, Trenholm HL (1992) Effect of deoxynivalenol on neurotransmitters in discrete regions of swine brain. Arch Environ Contam Toxicol 22(1):36-40. https://doi. org/10.1007/bf00213300

Salgado S, Kaplitt MG (2015) The nucleus accumbens: a comprehensive review. Stereotact Funct Neurosurg 93(2):75-93. https://doi. org/10.1159/000368279

Sayyari A, Framstad T, Krogenaes AK, Sivertsen T (2018) Effects of feeding naturally contaminated deoxynivalenol diets to sows during late gestation and lactation in a high-yield specific pathogenfree herd. Porcine Health Manag 4:26. https://doi.org/10.1186/ s40813-018-0102-9

Schothorst RC, van Egmond HP (2004) Report from SCOOP task 3.2.10 "collection of occurrence data of Fusarium toxins in food and assessment of dietary intake by the population of EU member states". Subtask: trichothecenes. Toxicol Lett 153(1):133-143. https://doi.org/10.1016/j.toxlet.2004.04.045

Schultz W (2015) Neuronal reward and decision signals: from theories to data. Physiol Rev 95(3):853-951. https://doi.org/10.1152/physr ev.00023.2014

Smith MO, Holland RC (1975) Effects of lesions of nucleus accumbens on lactation and postpartum behavior. Physiol Psychol 3(4):331-336

Turner PC, White KL, Burley VJ et al (2010) A comparison of deoxynivalenol intake and urinary deoxynivalenol in UK adults. Biomarkers 15(6):553-562. https://doi.org/10.3109/13547 50X.2010.495787

Wouters M, Smans K, Vanderwinden JM (2005) WZsGreen/+ : a new green fluorescent protein knock-in mouse model for the study of KIT-expressing cells in gut and cerebellum. Physiol Genomics 22(3):412-421. https://doi.org/10.1152/physiolgenomics.00105 .2005

Wu W, Zhou HR, Bursian SJ et al (2014) Comparison of anorectic and emetic potencies of deoxynivalenol (vomitoxin) to the plant metabolite deoxynivalenol-3-glucoside and synthetic deoxynivalenol derivatives EN139528 and EN139544. Toxicol Sci 142(1):167-181. https://doi.org/10.1093/toxsci/kfu166

Yager LM, Garcia AF, Wunsch AM, Ferguson SM (2015) The ins and outs of the striatum: role in drug addiction. Neuroscience 301:529-541. https://doi.org/10.1016/j.neuroscience.2015.06.033

Publisher's Note Springer Nature remains neutral with regard to jurisdictional claims in published maps and institutional affiliations. 